\title{
Wavelet Spectrogram Analysis of Surface Wave Technique for Dynamic Soil Properties Measurement on Soft Marine Clay Site
}

\author{
Sri Atmaja P. Rosyidi ${ }^{1}$ and Mohd. Raihan Taha ${ }^{2}$ \\ 1Universitas Muhammadiyah Yogyakarta \\ 2Universiti Kebangsaan Malaysia \\ ${ }^{1}$ Indonesia \\ ${ }^{2}$ Malaysia
}

\section{Introduction}

The surface wave measurement is one of in-situ seismic methods based on the dispersion of Rayleigh waves (R-waves) which is used to determine dynamic soil properties, i.e., the shear wave velocity $\left(V_{S}\right)$, shear modulus $(G)$, damping ratio (D) and depth of each layer of the soil profile. Much of the basis of the theoretical and analytical work of this method for soil investigation has also been developed (Stokoe et al., 1994). Seismic data used in surface wave analysis are non-stationary in nature, i.e., varying frequency content in time. Especially in the low frequency range measurement, i.e., in soft soil deposit, the interested frequency of surface wave can be relatively low, i.e., less than $20 \mathrm{~Hz}$. In these frequency values, the noisy signals from the natural or man-made sources may disturb the identical frequency level of the surface wave signals generated from the source. Therefore, a timefrequency decomposition of a seismic signal is needed to obtain the correct information of phase spectrum generated from signal transformation. In most of surface wave methods, the data analysis from time to frequency domain has been carried out by using Fourier transformation. However, some information of non-stationary seismic data in analysis maybe lost due to any arbitrary periodic function of time with period which is expressed as sum a set of sinusoidal in Fourier transform. The Fourier analysis is unable to preserve the time dependence. In addition, it also can not describe the evolutionary spectral characteristics of non-stationary processes. Thus, a new tool, i.e., wavelet analysis is required which allows time and frequency localization of the signals in the surface wave measurement beyond customary Fourier analysis.

Based on processing signal data at different scales or resolutions, wavelet analysis is becoming an important tool for identifying and analyzing localized variations of signal power, particularly it is well-suited for approximating data with sharp discontinuities within a time series. By decomposing a time series into time-frequency spectrum (TFW), one is able to determine both the dominant modes of variability and how those modes vary in time. The wavelet transform has been used in numerous studies, i.e., Meyers et al. (1993), Liu (1994), Weng \& Lau (1994), Wang \& Wang (1996) for climate and meteorological studies, Foufoula-Georgiou and Kumar (1995), Capilla (2006), Rosyidi et al. (2009) for geophysics, 
and Chik et al. (2009) and Rosyidi (2011) for civil engineering applications, respectively. Theoretical aspect of wavelets is given in many essential literatures such as Daubechies (1992), Mallat (1999), Soman and Ramachandran (2005). From their studies, the wavelet analysis has been successfully proven as an interactive technique for analyzing the waveforms and non-stationary characteristic of generated seismic signals from the surface wave measurements. Capilla (2006) used Haar wavelet transform application on the detection of micoseismic signal arrival. The results showed that the seismic series is able to be derived from an ensemble of subprocesses operating at characteristic scales and with time dependent variability from the wavelet approach where the discontinuous Haar wavelet decomposition shows the capability for efficiently extracting and locating emphasis the higher frequency in time sudden transitions associated with the transient events. Rosyidi et al. (2009) also conducted the study on the identification and reconstruction of the wave response spectrum from seismic surface wave propagation on a Malaysian residual soil using time-frequency analysis of the continuous wavelet transforms. Their results showed that the wavelet analysis is useful in spectral analysis, time-frequency decomposition for the identification of transient events in non-stationary signal and filtering of noisy signals in seismic surface waves records. In surface wave measurements, the application of wavelet analysis has been started by Kim and Park (2002) who used a harmonic wavelet transform for determining dispersion curve in the spectral analysis of surface wave (SASW) method. Their results showed that a new procedure based on wavelet transform was proposed for calculating the phase and group velocities at each frequency independent of remaining frequency components using the information around the time at which the signal energy. The method was also less affected by noise and near field effect than the phase unwrapping method that used as a common procedure in the surface wave measurement. Kritski et al. (2007) proposed a mathematical model to establish a relationship between the continuous wavelet transform of a signal and its propagated counterpart in a dispersive and attenuating medium. Their results showed that the wavelet model is able to estimate both phase and group velocities, as well as the attenuation coefficient. In addition, Shokouhi et al. (2003) explained the advantages of the wavelet approach in the SASW measurement, i.e., detection and characterization of cavities and objects buried in the ground and characterization of layer interfaces, with respect to layer dipping and abrupt interface changes.

The aim of this research is to improve the capability of in-situ surface wave measurement by developing the wavelet spectrogram analysis of surface waves (WSASW) technique for measurement of the soil dynamic properties, i.e., the shear wave velocity, shear modulus, and damping ratio at soft marine clay soils sites. This technique has capability to reconstructed spectrograms of noisy seismic waves and produces the enhanced phase data to develop the phase velocity dispersion curve. In soft soil site, the environmental noises are dominant in the recorded seismic signals due to the wave frequency of interest are identical to the frequency level of noisy signals. Therefore, the time-frequency wavelet spectrum is employed to localise the interested response spectrum of surface waves. A filtration procedure is also proposed in order to remove the noisy signals from the seismic records which were captured during field measurement.

In this research, a test site at Radio Televsyen Malaysia (RTM), Kelang, Malaysia was selected as location of measurement (Fig. 1). The site is a fairly flat open paddy field and an on going construction was seen about $500 \mathrm{~m}$ away from the site. The site is generally an original ground and the soil mass is mainly of greyish clay. The regional geology of the site 
has been classified as recent quaternary of dominantly alluvial deposits of soft marine clay with traces of organics. The soil descriptions from the two boreholes at the location have also shown that the soil type found were quite similar with the geology classification, i.e., greyish clay with decayed wood at most of the soil layers of the subsoil stratum (Fig. 2).

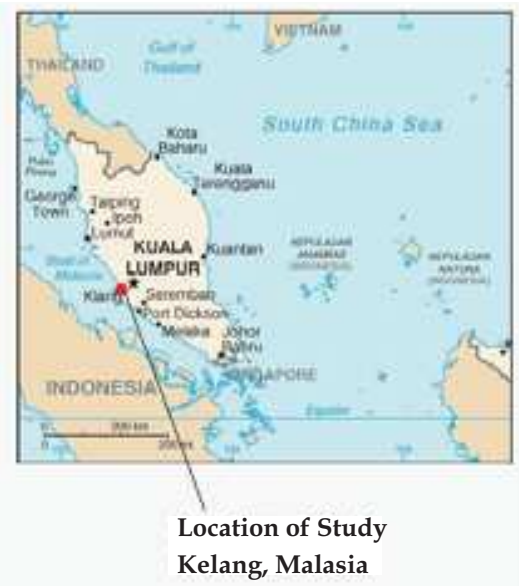

Map source: The World Factbook (2009)

Central Intelligence Agency, Washington, D.C

http://www.cia.gov/library/publications/the-world-fact book/index.html

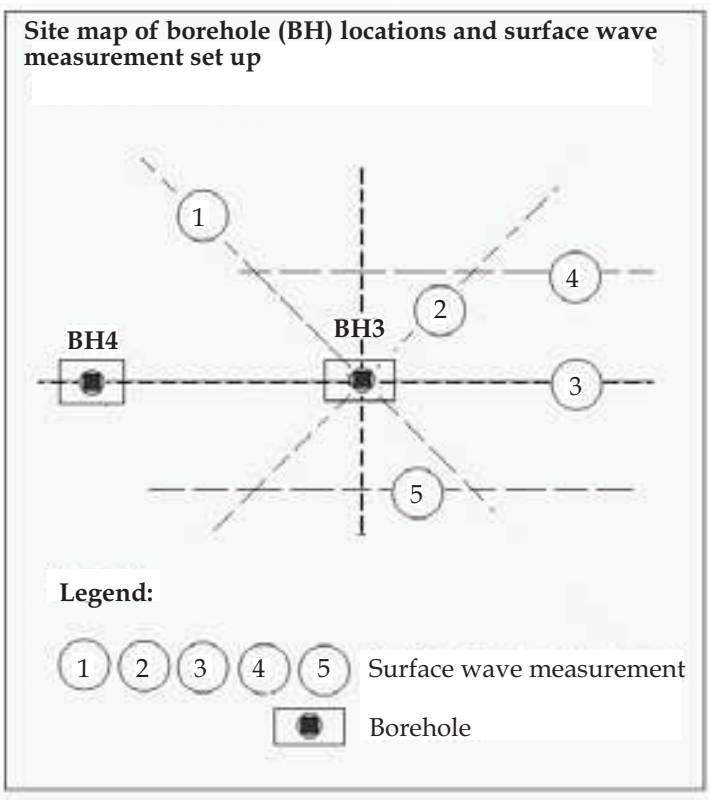

Fig. 1. Location of study

\section{Research method}

In the proposed WSASW technique, there are four main stages as described in the following sections.

\subsection{Field measurement}

In this study, the seismic signal data were collected by using the SASW field measurement set up. There are three important set ups in the SASW measurement for soft soil location, i.e., adequate wave frequencies produced from the various impact sources, capability of receivers or geophones to receive the interested frequency and the appropriate acquisition unit or spectrum analyser used in the measurement. A set of impact hammer sources of various frequencies was used to generate $R$ waves on the soil surface. The propagation of the waves were detected using two receiving geophones and the analog signals were then transmitted to a spectrum analyser which consisted of acquisition box and transferred digitally to a notebook computer (Fig. 3).

Sledge hammers of 8 and $12 \mathrm{~kg}$ were used as transient impact sources in the SASW measurement. One of advantages using an impact (transient) source is to generate and measure a broad range of frequencies simultaneously. However, the frequency content is 
often limited and it is also important to realise that different transient sources generate energy over different frequency ranges. Prior to the experiments, a pilot study on frequency range test on transient hammers used in this study was carried out. The hammer generated surface waves over different frequency range with adequate amplitude and they were able to be detected by the receiver. For a typical soil deposit, the highest frequency necessary is in the order of 200 to $800 \mathrm{~Hz}$ (Nazarian, 1984). Therefore, the selected sledge hammers in this research are appropriate to be used for sampling the soft soil layer up to approximately 5 meter of depth.

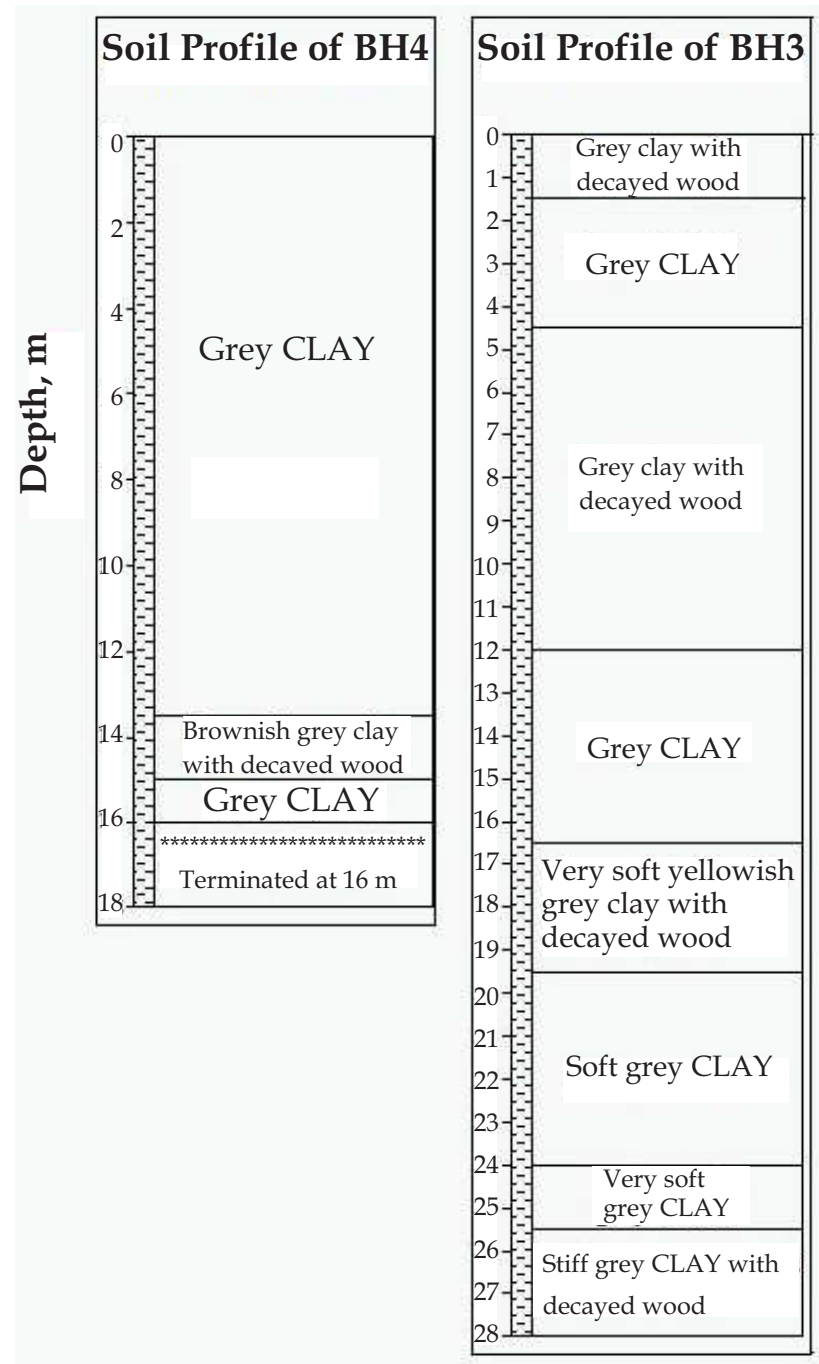

Fig. 2. Borehole data of $\mathrm{BH} 3$ and $\mathrm{BH} 4$ from location of study (Fig. 1) 


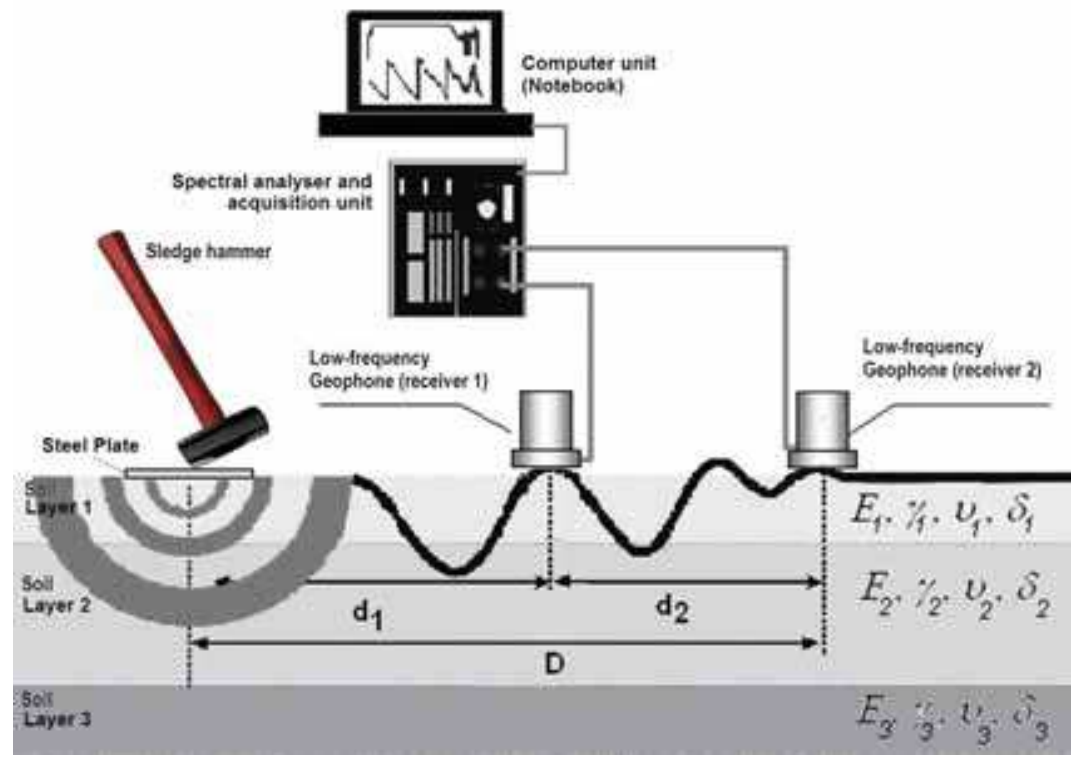

Fig. 3. SASW measurement setup applied on the soil sites

Vertical geophones of $1 \mathrm{~Hz}$ used in this study only receive the vertical displacement of the generated signal from the impact sources as the interested component in the measurement. Several configurations of the receiver and the source spacings were required in order to sample different depths. The measurement configuration of the SASW test used in this study is the midpoint receiver spacings. In addition, the short receiver spacings with a high frequency source were used to sample the shallow layers of the soil profile. Larger receiver spacings with a set of low frequency sources were employed to sample the deeper layers. The distance between the source and the near receiver was set up equal to the distance between the receivers (Fig. 3). This configuration is adequate for reducing the near-field effect (Heisey et al., 1982; Ganji et al., 1998).

\subsection{Development of experimental phase velocity dispersion curve}

An experimental phase velocity dispersion curve from all receiver spacings in one configuration measurement was generated based on the phase angle data from the both signals received by geophones. However, in fact, the phase angle is difficult to be interpreted from the noisy signals because it should be analyzed from huge amounts of nonstationary seismic data in nature i.e. varying frequency content in time. Therefore, the timefrequency localization is needed to provide accurate information of wave spectrum. In this study, the time-frequency analysis of continuous wave transform (CWT) was employed for localizing and filtering the interested wave spectrum.

\subsubsection{Continuous wavelet transform (CWT)}

The continuous wavelet transform (CWT) technique is becoming a common tool to analyse localised variation of power within a time series for non-stationary signal, i.e., seismic 
signals. In the technique, wavelets dilate in such a way that the time component also changes for different frequency. When the time window component of the wavelet decreases or increases, the frequency component of the wavelet is shifted towards high or low frequencies, respectively. Therefore, as the frequency resolution increases, the time resolution decrease and vice versa, which is called as multi resolution analysis, analysing the signal at different frequencies with different resolutions (Mallat, 1989). CWT offers good spectral and poor temporal resolution at low frequency, which is useful for low frequency analysis with long duration signals, and good temporal and poor spectral resolution at high frequency which is valuable for high frequency signals with short duration. This optimal time-frequency resolution property makes the CWT technique useful for non-stationary seismic analysis.

A wavelet is defined as a function of $\psi(t) \in L^{2}(\Re)$ ( $L^{2}$ is the set of square integrable function) with a zero mean, which is finite energy signals in both time and frequency. By dilating and translating the wavelet $\psi(t)$, a family of wavelets can be produced as:

$$
\psi_{\sigma, \tau}(\tau)=\frac{1}{\sqrt{\sigma}} \psi\left(\frac{t-\tau}{\sigma}\right)
$$

where $\sigma$ is the dilation parameter or scale and $\tau$ is the translation parameter $(\sigma, \tau \in \mathfrak{R}$ and $\sigma$ $\neq 0)$. The CWT is defined as the inner product of the family wavelets $\Psi_{\sigma, \tau}(t)$ with the signal of $\mathrm{f}(\mathrm{t})$ which is given as:

$$
F_{W}(\sigma, \tau)=\int_{-\infty}^{\infty} f(t) \frac{1}{\sqrt{\sigma}} \bar{\psi}\left(\frac{t-\tau}{\sigma}\right) d t
$$

where $\bar{\psi}$ is the complex conjugate of $\psi$ and $F_{W}(\sigma, \tau)$ is the time-scale map. The convolution integral from equation 2 can be computed in the Fourier domain. To reconstruct the function $f(t)$ from the wavelet transform, Calderon's identify (Daubechies, 1992) can be used and is obtained as:

$$
\begin{gathered}
f(t)=\frac{1}{C_{\psi}} \int_{-\infty}^{\infty} \int_{-\infty}^{\infty} F_{W}(\sigma, \tau) \psi\left(\frac{t-\tau}{\sigma}\right) \frac{d \sigma}{\sigma^{2}} \frac{d \tau}{\sqrt{\sigma}} \\
C_{\psi}=2 \pi \int \frac{|\hat{\psi}(\omega)|^{2}}{\omega} d \omega<\infty
\end{gathered}
$$

where $\hat{\psi}(\omega)$ is the Fourier transform of $\psi(t)$. The integrand in equation 4 has an integrable discontinuity at $\omega=0$ and implies that $\int \psi(t) d t=0$. In this study, the mother wavelet of the Morlet wavelet was used. The shape of the Morlet wavelet is a Gaussian-windowed complex sinusoid. It is defined in the time and frequency domains as follows:

$$
\begin{gathered}
\Psi_{0}(t)=\pi^{-1 / 4} e^{i m t} e^{-t^{2} / 2} \\
\hat{\psi}_{0}(s \omega)=\pi^{-1 / 4} H(\omega) e^{-(s \omega-m)^{2} / 2}
\end{gathered}
$$


where $m$ is the wavenumber, and $H$ is the Heaviside function. The time and frequency domain plot of Morlet wavelet is shown in Fig. 4. In Figure 4a, the Morlet wavelet is shown within an adjustable parameter $m$ of 7 which is used in this study. This parameter can be used for an accurate signal reconstruction of seismic surface waves in low frequency. The Gaussian's second order exponential decay used in time resolution plot results in the best time localisation.

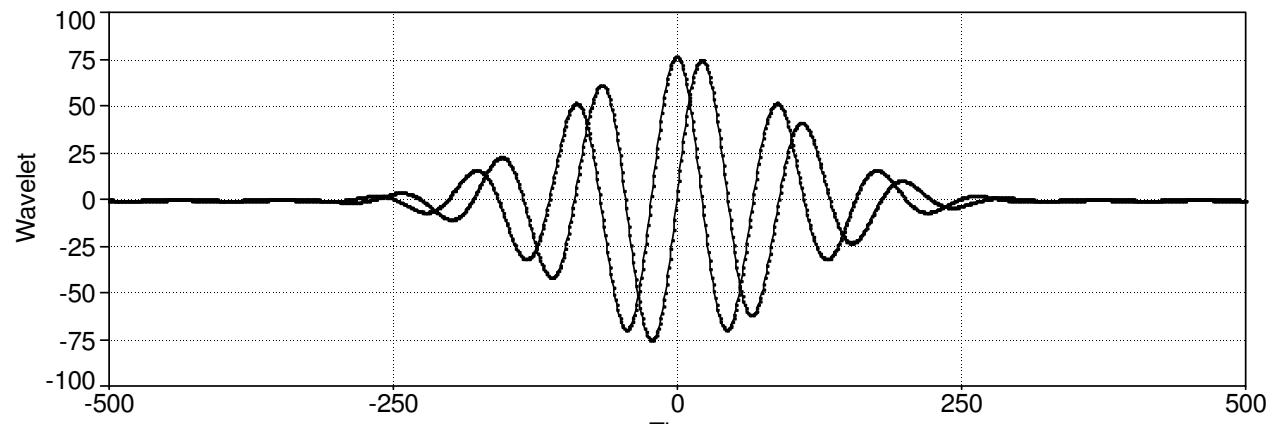

(a) Time domain of real and imaginary part

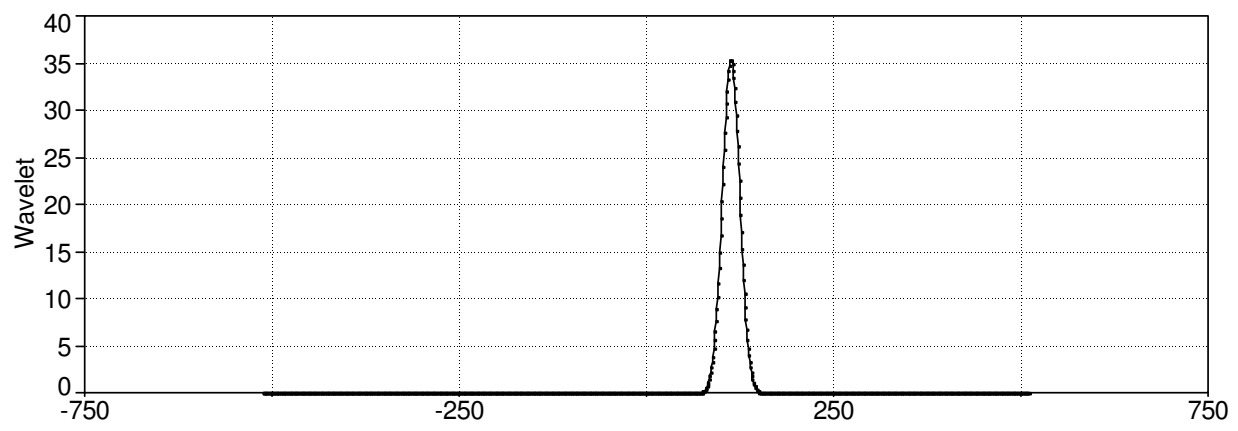

(b) Frequency domain

Fig. 4. Time and frequency domain plot of Morlet wavelet

\subsubsection{Proposed procedure of the CWT technique in surface waves analysis}

A flow chart of procedure of the CWT technique in the WSASW method is described in Figure 5. The detail procedure is discussed in the following section.

1. Select the wavelet function and a set of scale, s, to be used in the wavelet transform. The different wavelet function may influence the time and frequency resolution. In this study, a Morlet wavelet function was selected as a mother wavelet in the CWT filtering.

2. Develop the wavelet scalogram by implementing the wavelet transform (equation 2) using computed convolution of the seismic trace with a scaled wavelet dictionary. Scalogram is a local time-frequency energy density which measures the energy of the signals in the Heisenberg box of each wavelet. The detail discussion of scalogram can 
refer to Mallat (1989). Wavelet scale is calculated as fractional power of 2 using the formulation (Torrence \& Compo, 1998):

$$
\begin{gathered}
s_{j}=s_{0} 2^{j \delta_{j}}, j=0,1, \ldots, J \\
J=\delta j^{-1} \log _{2}\left(\frac{N \delta_{t}}{s_{0}}\right)
\end{gathered}
$$

where, $s_{0}$ is smallest resolvable scale $=2 \delta t, \delta t$ is time spacing, and $J$ is largest scale.

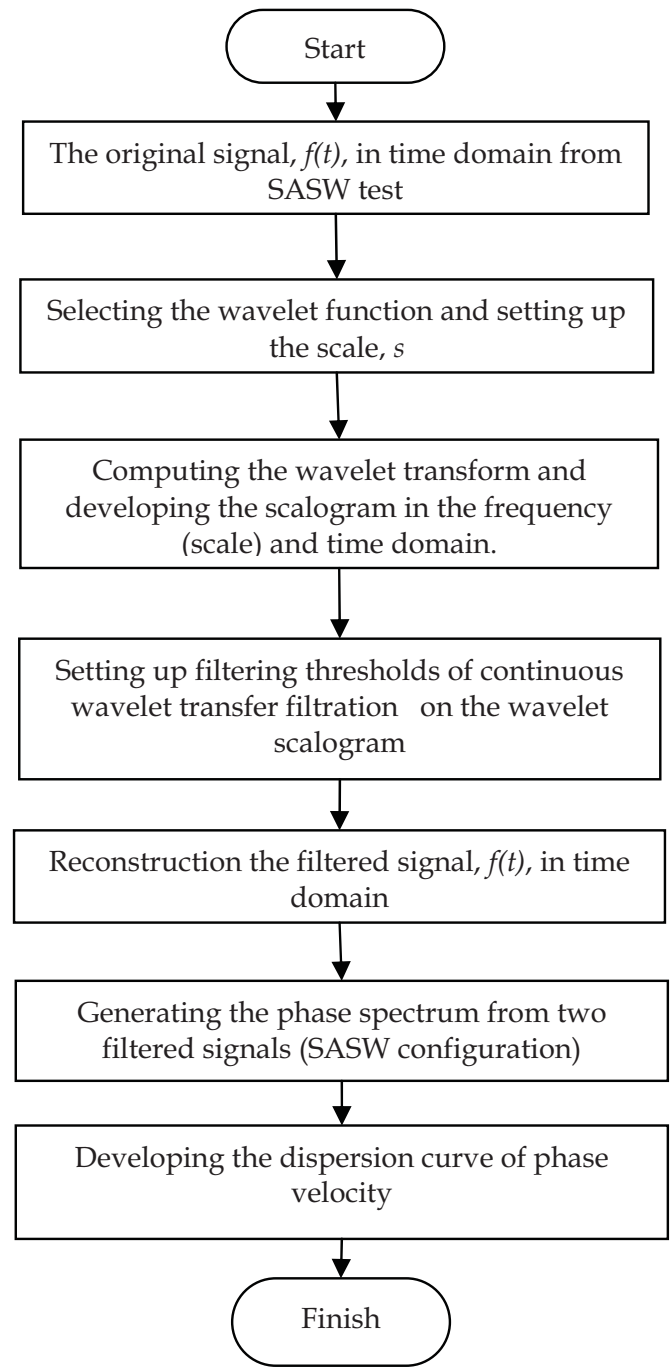

Fig. 5. Flow chart of CWT Filtering procedure 
3. Convert the scale dependent wavelet energy spectrum (scalogram) of the signal to a frequency dependent wavelet energy spectrogram in order to compare directly with Fourier energy spectrum.

4. Perform the CWT filtration on the wavelet spectrogram by obtaining the time and frequency localization thresholds. Wavelet spectrogram is developed from the scalogram which allows the filtration technique implemented directly to the spectrum. In this study, the CWT filtration was developed by a simple truncation filter concept which only considers the passband and stopband. Threshold values in time and frequency domain are then set as the filter values between passband and stopband. It allows a straight filtering in each of the dimensions of times, frequencies and spectral energy. The noisy or unnecessary signals can be eliminated by zeroing the spectrum energy and consequently, they are fully removed when reconstructing the time domain signal. Thus, the interested spectrum of signals are to be passed when the spectrum energy is maintained in original value. A design of the CWT filtration is proposed by Rosyidi (2009) and can be written as:

$$
\begin{array}{r}
f(s)= \begin{cases}0, & 1 \leq s \leq F_{l} \\
1, & F_{l} \leq s \leq F_{h} \\
0, & F_{h} \leq s \leq N\end{cases} \\
f(u)= \begin{cases}0, & 1 \leq u \leq T_{l} \\
1, & T_{l} \leq u \leq T_{h} \\
0, & T_{h} \leq u \leq N\end{cases}
\end{array}
$$

5. The value of 1 means the spectrum energy is passed and the value of 0 represents the filtration criteria when the spectrum energy is set as 0 .

6. Reconstruct the time series of seismic trace using equation 3.

7. Calculate the phase different from reconstructed signals at each frequency to develop the phase spectrum for the experimental dispersion curve. The phase data can be calculated from:

$$
\phi_{n}(s)=\arctan \left(\frac{\mathfrak{I}\left\{s^{-1} W_{n}^{X Y}(s)\right\}}{\mathfrak{R}\left\{s^{-1} W_{n}^{X Y}(s)\right\}}\right)
$$

where,

$$
W_{n}^{X Y}(s)=W_{n}^{X}(s) W_{n}^{Y *}(s)=\text { wavelet cross spectrum }
$$

8. Finally, by extracting the data of the phase angle from the phase spectrum, a composite experimental dispersion curve can be calculated by the phase difference method. The time of travel between the receivers for each frequency can be calculated by:

$$
t(f)=\frac{\phi(f)}{(360 f)}
$$

where $f$ is the frequency, $t(f)$ and $\phi(f)$ are, respectively, the travel time and the phase difference in degrees at a given frequency. The distance of the receiver $(d)$ is a known 
parameter. Therefore, the Rayleigh wave velocity, $V_{R}$ or the phase velocity at a given frequency is simply obtained by:

$$
V_{R}=\frac{d}{t(f)}
$$

and the corresponding wavelength of the Rayleigh wave, $L_{R}$ may be written as:

$$
L_{R}(f)=\frac{V_{R}(f)}{f}
$$

By repeating the procedure outlined above and using equation 13 through 15 for each frequency value, the $\mathrm{R}$ wave velocity corresponding to each wavelength is evaluated and the experimental dispersion curve is subsequently generated.

\subsection{Shear wave velocity profile}

An inversion analysis was used to generate the shear wave velocity profile. In the inversion process, a profile of a set of a homogeneous soil layer extending to infinity in the horizontal direction was assumed. The last layer is usually taken as a homogeneous half-space. Based on the initial profile, a theoretical dispersion curve was constructed using an automated forward modeling analysis involving 3-D dynamic stiffness matrix method (Kausel \& Röesset, 1981). In the model, displacements and stresses (or traction) of the propagation of the waves on a horizontal surface can be expanded using the Fourier series in the circumferential direction and in terms of cylindrical function (Bessel, Neuman or Hankel functions) in the radial direction.

For axisymmetric loading only one Fourier series term is needed (the 0 term), and the radial and vertical displacements $(U$ and $W$ ) can be expressed by:

$$
\begin{gathered}
U(r)=q R \int_{k=0}^{\infty} \bar{u} J_{1}(k R) J_{1}(k r) d k \\
W(z)=q R \int_{k=o}^{\infty} \bar{w} J_{1}\left(k R_{o}\right) J_{0}(k r) d k
\end{gathered}
$$

where $J_{0}$ and $J_{1}=$ the zero and the first order Bessel function, $k=$ the wave number, $r=$ the radial distance from the source, $R=$ the radius of the disk, $q=$ the magnitude of the uniformly distributed load; $\bar{u}$ and $\bar{w}=$ functions of $k$ for a harmonic load at the surface with wavelength $2 \pi / k$. Kausel \& Röesset (1981) showed that the displacement $\bar{u}$ and $\bar{w}$, in Equation 16, can be written as:

$$
\begin{gathered}
\bar{u}=\sum_{i=1}^{2 n+2} u_{i 1} w_{i 1} \frac{k}{k_{i}\left(k^{2}-k_{i}^{2}\right)} \\
\bar{w}=\sum_{i=1}^{2 n+2} w_{i 1}^{2} \frac{k}{k_{i}\left(k^{2}-k_{i}^{2}\right)}
\end{gathered}
$$


For a system of $n$ layers over a half-space, $u_{i 1}$ and $w_{i 1}$ denote the horizontal and vertical displacements at the surface in the $i^{\text {th }}$ mode and can be found from the corresponding mode shape. By substituting equation 18 and 19 to 16 and 17, respectively the integral can be evaluated analytically in closed form. This solution is particularly convenient when dealing with a large number of layers as in the case when it is desired to obtain a detailed variation of the soil properties. Subsequently, the theoretical dispersion curve generated using the 3-D model was ultimately matched to the experimental dispersion curve based on lowest root mean square (RMS) error with an optimisation technique from Joh (1996).

\subsection{Development of soil shear modulus and damping ratio profile}

The soil shear modulus profile can be obtained by linear elastic model involving the parameter of the shear wave velocity obtained from inversion process as mentioned in previous section. The soil shear modulus is calculated from the following equation (Kramer, 1996):

$$
G=\frac{\gamma V_{S}^{2}}{g}
$$

where $G=$ the dynamic shear modulus, $V_{S}=$ the shear wave velocity, $g=$ the gravitational acceleration; and $\gamma=$ the total unit weight of the material. Nazarian \& Stokoe (1986) explained that the modulus parameter of material is maximum value at a strain below about $0.001 \%$. In this strain range, modulus of the materials is also taken as constant.

In order to measure the soil attenuation from signals recorded from field measurement, the spectrogram attenuation model developed by Rosyidi (2009) was employed in the analysis. The decrease in amplitude (energy density) of the vertical component of the Rwave with distance due only to geometric configuration is also called the radiation damping or geometric spreading. An effective soil damping ratio of R-wave in layered medium can be defined from the attenuation analysis and the value is frequency dependent. Its value may become very high for the first few modes of vibration. The attenuation $(\alpha)$ of R-wave can be performed by the spectrogram attenuation model proposed by Rosyidi (2009) as follows:

$$
\ln \left[\frac{W_{f}^{R_{2}}(u, s)}{W_{f}^{R_{1}}(u, s)}\right]=\ln \left[\left\{\frac{R_{1}}{R_{2}}\right\}^{n}\{G(R) \cdot G(I) \cdot K(R)\} e^{\left\{-\alpha(f)\left(R_{1}-R_{2}\right)\right\}}\right]
$$

where, $R_{1}$ dan $R_{2}=$ geophones distance from the sources (if using two geophones), $W_{f}^{R_{1}}(u, s)$ dan $W_{f}^{R_{2}}(u, s)=$ spectrogram magnitude response for geophone 1 and 2 respectively, $G(R)$ = geometric spreading factor, $G(I)=$ instrumentation correction factor and $K(R)=$ correction for refracted and transmitted waves.

Finally, the experimental attenuation curves can be used in the inversion process aimed in estimating the variation of soil shear damping ratio with depth. The inversion process is carried out using the SURF code (Herrmann, 1994), based on a weighted, damped, leastsquares algorithm. Experimental attenuation curve consists of surface-wave attenuation data at different frequencies obtained from equation 21 . The amplitude variation with distance can be used to obtain the experimental attenuation curve. 
The solution to the inversion problem of estimating the dissipation factors is based on (Aki \& Richards, 1980):

$$
\alpha(f)=\frac{2 \pi f}{V_{R}^{2}}\left\{\sum_{i}^{N} V_{P, i}\left(\frac{\partial V_{R}}{\partial V_{P}}\right)_{i} D_{P, i}+\sum_{i}^{N} V_{S, i}\left(\frac{\partial V_{R}}{\partial V_{S}}\right) D_{S, i}\right\}
$$

where $V_{P}, V_{S}$ and $V_{R}$ are the P-, S- and Rayleigh-wave velocities, respectively. The suffix $i$ refers to the $i$ th layer and the summation is carried out over $\mathrm{N}$ layers of the stratified soil model. $D_{P}$ and $D_{S}$ are the damping ratio values for $\mathrm{P}$ - and S-waves, respectively.

In homogeneous media with high values of Poisson's ratio (v), the influence of the P-wave damping ratio on Rayleigh-wave attenuation is very small (Viktorov, 1967). For layered media, the influence of $D_{P}$ on Rayleigh-wave attenuation is negligible for values of $V_{P} / V_{S}$ greater than 2 (i.e. $v>1 / 3$ ) as described in Xia et al. (2002). These values are typical for saturated soils, and in many temperate regions the water table is usually shallow, thus it is reasonable to perform the inversion of Rayleigh-wave attenuation assuming a constant value of the ratio $D_{P} / D_{S}$ or assuming that no bulk loss is present (Herrmann, 1994, Foti, 2004). It is important to point out that the relationship between the attenuation of Rayleigh waves and the dissipative properties of each layer is influenced by the shearwave velocity profile of the medium. The detail procedure of the inversion process for obtaining the shear damping ratio is discussed by Herrmann (1994), Lai and Rix (1998) and Foti (2004).

\section{Results and discussion}

\subsection{Seismic data and spectrum analysis}

Figure 5 shows two examples of the recorded signals from averaging multiple impacts from the field seismic measurement at soil test site. The signals were received by two geophones in $8 \mathrm{~m}$ receiver spacing. From the recorded signals, it can be recognised that higher amplitude is measured for the fundamental mode of $R$ - wave amplitude. It is also noted that the decreasing signal magnitude is identified as the $R$-wave attenuation in the soil layer which is an important characteristic for energy decrement. The waveform of seismic signal recorded (Fig. 5) is transient and-non stationary. Weak recorded signal of seismic wave particularly in channel 2 is also identified as an effect of environmental noise which maybe produced from ground noise and man-made vibrations. This means that either the input signals or behaviour of system at different moments in time was not identical.

When the signals were transformed into frequency domain using FFT (fast Fourier transform), time-dependent behaviour of the seismic waves and noisy events were lost (Fig. 6). The energy content of these events which are present at different times and frequency would not be picked up by conventional Fourier analysis. In the other words, the conventional spectral analysis of non-stationary signal of seismic waves cannot describe the local transient event due to averaging duration of signals. It also cannot instantly separate the event of true seismic waves from noisy signals. Consequently, it is difficult to capture the correct phase information in the transfer function of both signals (Fig. 7). 


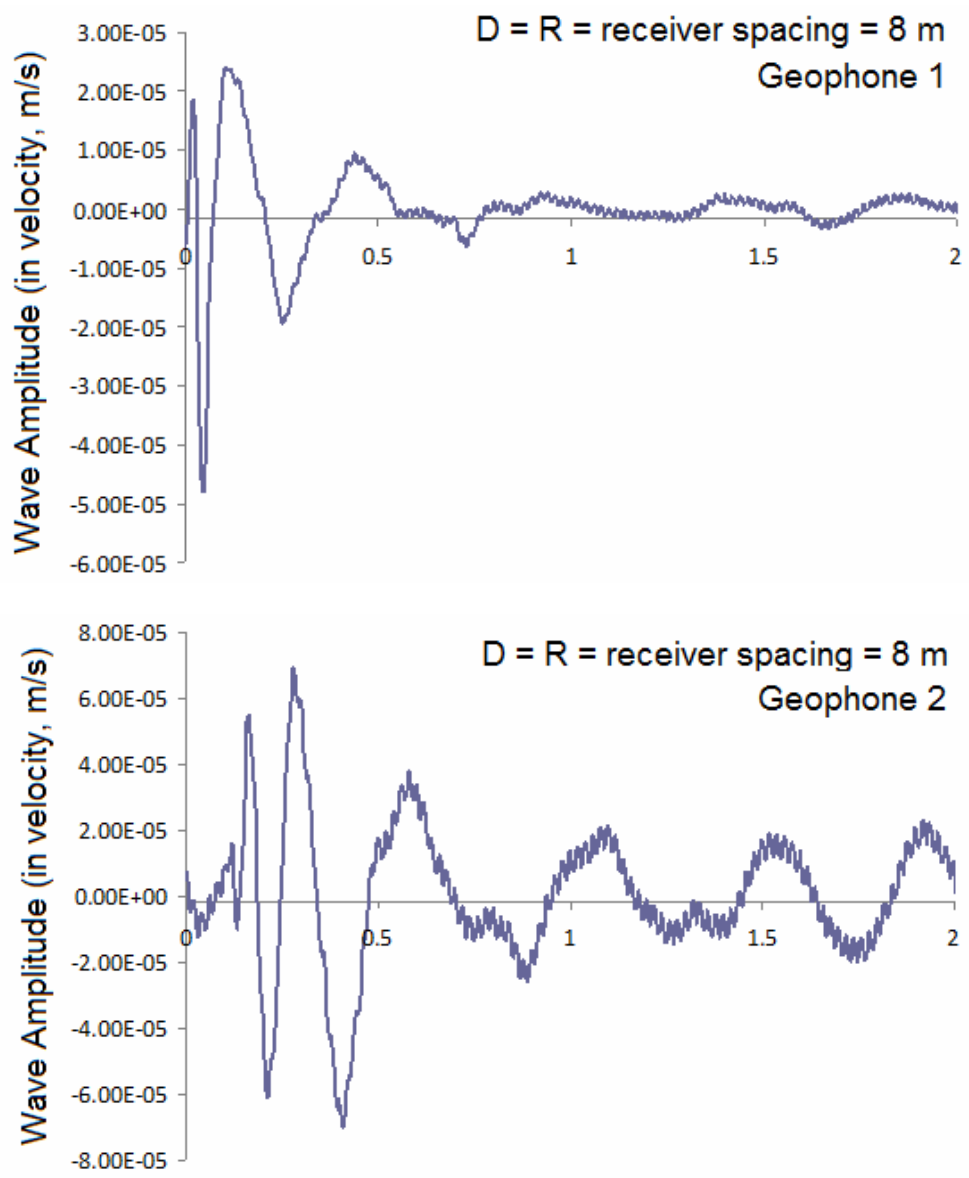

Time, second (s)

Fig. 5. The time signals from $8 \mathrm{~m}$ receiver spacing from the measurement

\subsection{CWT filtering and analysis in the WSASW}

In order to enhance the pattern of non-stationary seismic wave signals from noisy signal, both signals were then transformed in time-frequency resolution by the CWT. This time and frequency analysis of CWT was employed to overcome the identification problem of spectral characteristics of signals. Fig. 8 and 9 present the CWT spectrogram of the time signal from geophone 1 and geophone 2, respectively (Fig. 5), which was constructed by using a mother wavelet of Morlet.

Three main energy events at different frequency bands were clearly detected which may result in both low and high mode of seismic and noisy signals (Figure 8 and 9). It can be seen that coherent low frequency energy was found in the range of up to $2-10 \mathrm{~Hz}$ in both CWT spectrograms (event $\mathrm{B}, \mathrm{C}, \mathrm{D}, \mathrm{E}$ ). This spectrum range is clearly captured and identified 


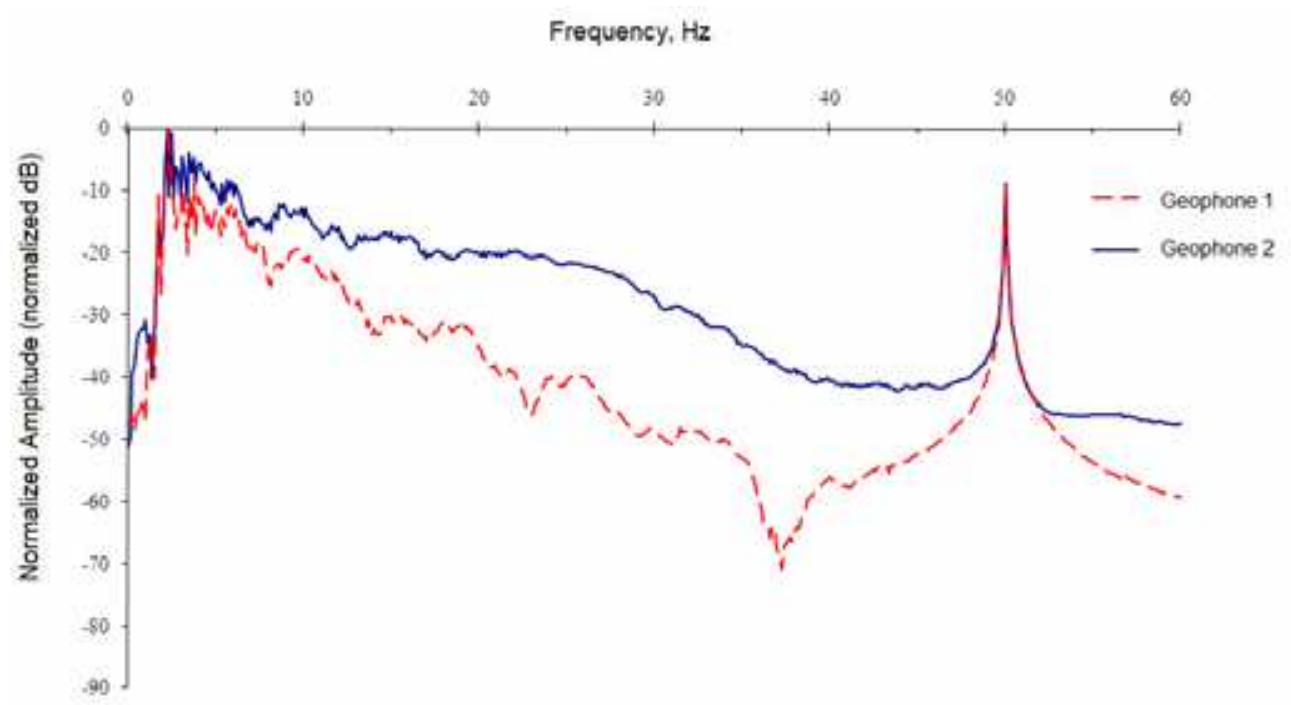

Fig. 6. FFT spectrum of the time signals from $8 \mathrm{~m}$ receiver spacing of the measurement

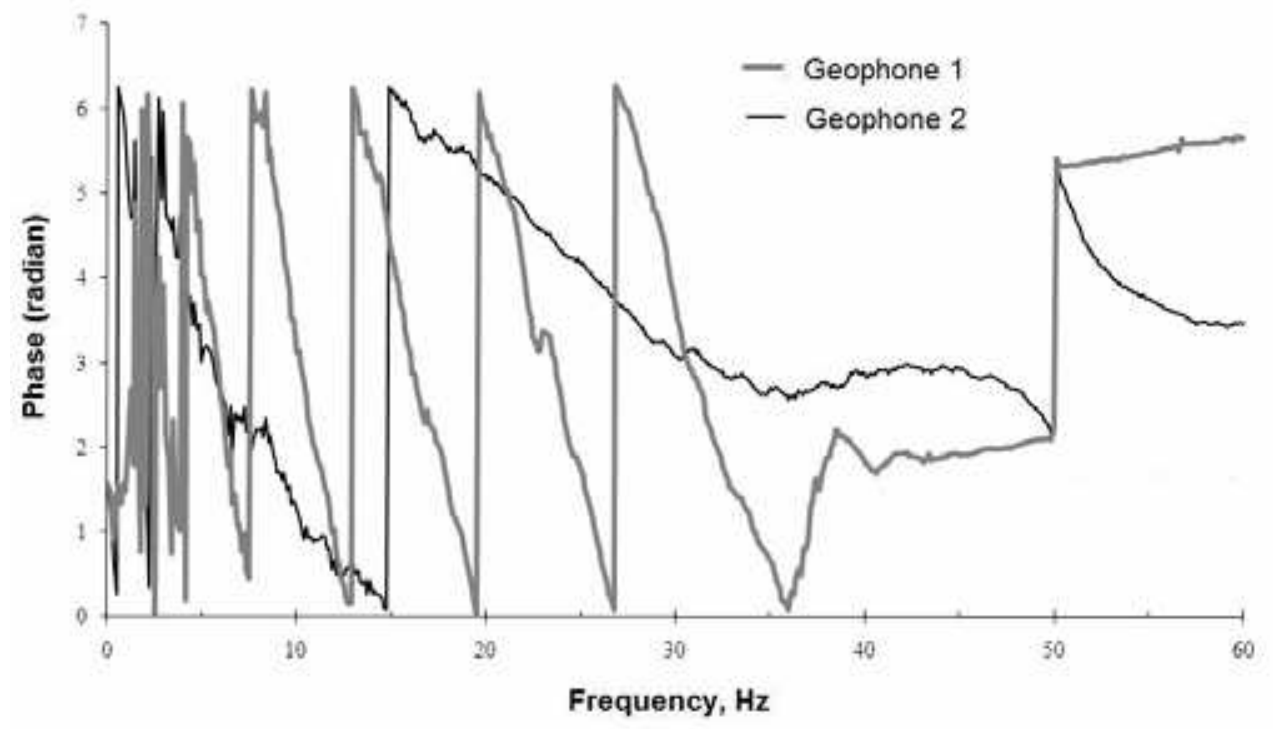

Fig. 7. Phase spectrum of each time signals from $8 \mathrm{~m}$ receiver spacing

as dominant noisy signals or ground rolls. Another noisy signal received during measurement was generated from the electrical devices and generator which has constantly the frequency content of $50 \mathrm{~Hz}$ (event F). The spectrum events of surface wave signals are recognized at event A with the frequency level of 4 to $35 \mathrm{~Hz}$ with arrival time of 0.012 to 0.50 $s$ which consist of high magnitude of energy. 

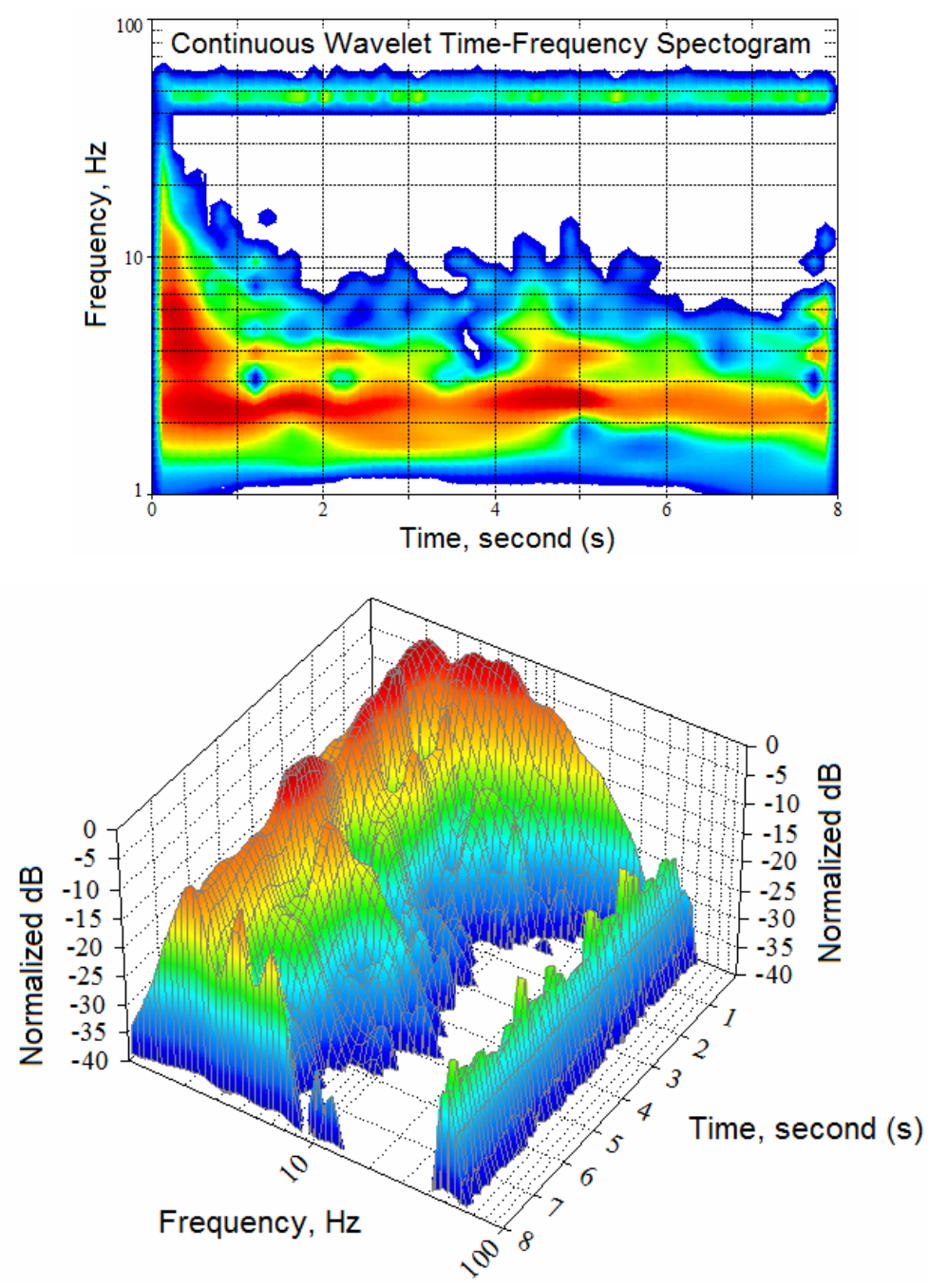

Fig. 8. The CWT spectrogram for signals received by geophone 1

In order to separate the original seismic wave, the wavelet spectrogram filtration was then implemented. There are two primary ways to set the thresholds for wavelet filtering. The first is to define a region of time-frequency space. This is primarily used to isolate and reconstruct signal components. The time and frequency fields define limits in spectrogram filtering. In this study, the time and frequency range of noise signal was set as threshold of wavelet (equation $9 \& 10$ ). It means that the noisy signals are removed from the spectrogram and only the interested seismic wave signals remain. Table 1 shows an example of the threshold parameters of time-frequency used in filtering criteria for the signals from $8 \mathrm{~m}$ receiver spacing of SASW measurement. Consequently the inverse wavelet transform returns a denoised seismic signal from the filtered spectrogram of interest. Demonstration of 
the wavelet analysis in denoising and reconstructing the recorded seismic signals is shown in Fig. 10. Particularly for seismic signal recorded on channel 2, the reconstructed waveform of denoised signal improves the signal pattern of the seismic surface waves. The highest amplitude shown at first phase of signals are recognised as low frequency energy from the noisy signals or ground rolls based on the spectrogram analysis, therefore, it should be filtered.

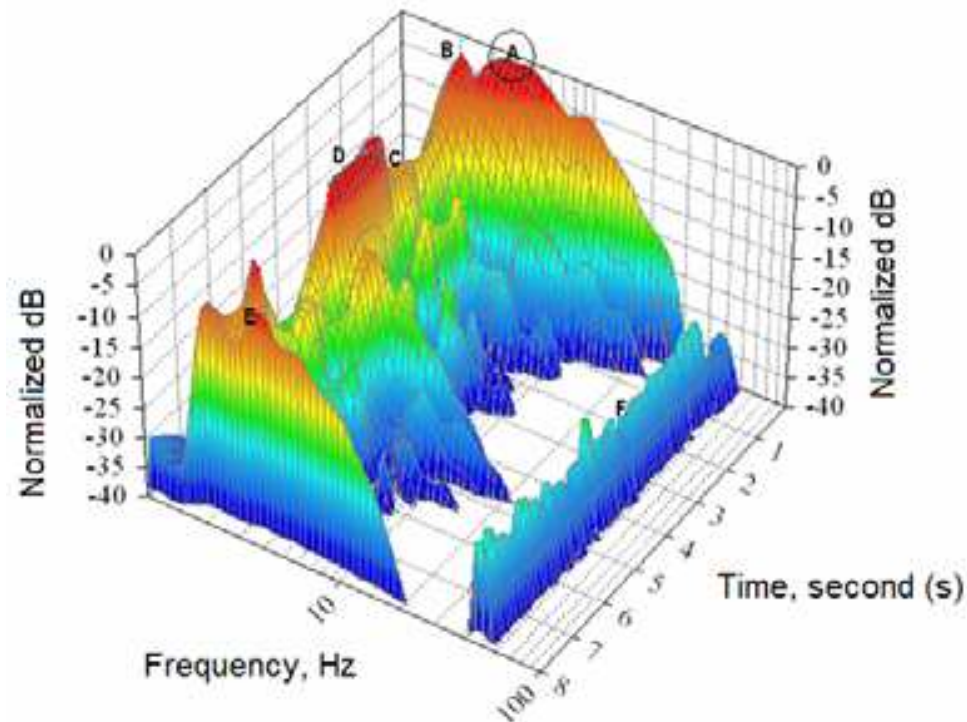

Fig. 9. The CWT spectrogram for signals received by geophone 2

\begin{tabular}{|c|c|c|c|c|}
\hline Threshold & \multicolumn{2}{|c|}{ Time (s) } & \multicolumn{2}{c|}{ Frequency (Hz) } \\
\hline & $T_{1}$ & $T_{2}$ & $F_{1}$ & $F_{2}$ \\
\hline Geophone 1 & 0.030 & 0.650 & 2.97 & 7.08 \\
\hline Geophone 2 & 0.002 & 0.440 & 2.75 & 6.05 \\
\hline
\end{tabular}

Table 1. Time and frequency threshold in CWTF

The phase spectrum from denoised signals from the surface wave measurement was then constructed by equation 11. Compared to the phase spectrum from original signals, the enhanced phase spectrum from the CWT filtration provides the better phase information versus frequency range without noisy interference needed in the surface wave analysis (Fig. 11). It shows that the CWT and wavelet filtering is an effective tool for identifying, denoising and reconstructing the noisy seismic surface waves measured on the soil profile. Finally, based on the phase different method (Equation 13 - 15), a phase velocity dispersion curve from enhanced phase spectrum can be obtained. Fig. 12 presents the dispersion curves obtained from CWTF compared to the original dispersive velocity data (only produced from masking process without any filtration), and dispersion curves from the continuous surface wave (CSW) measurement and the impulse response filtration (Joh, 1996) analysed from WinSASW. 

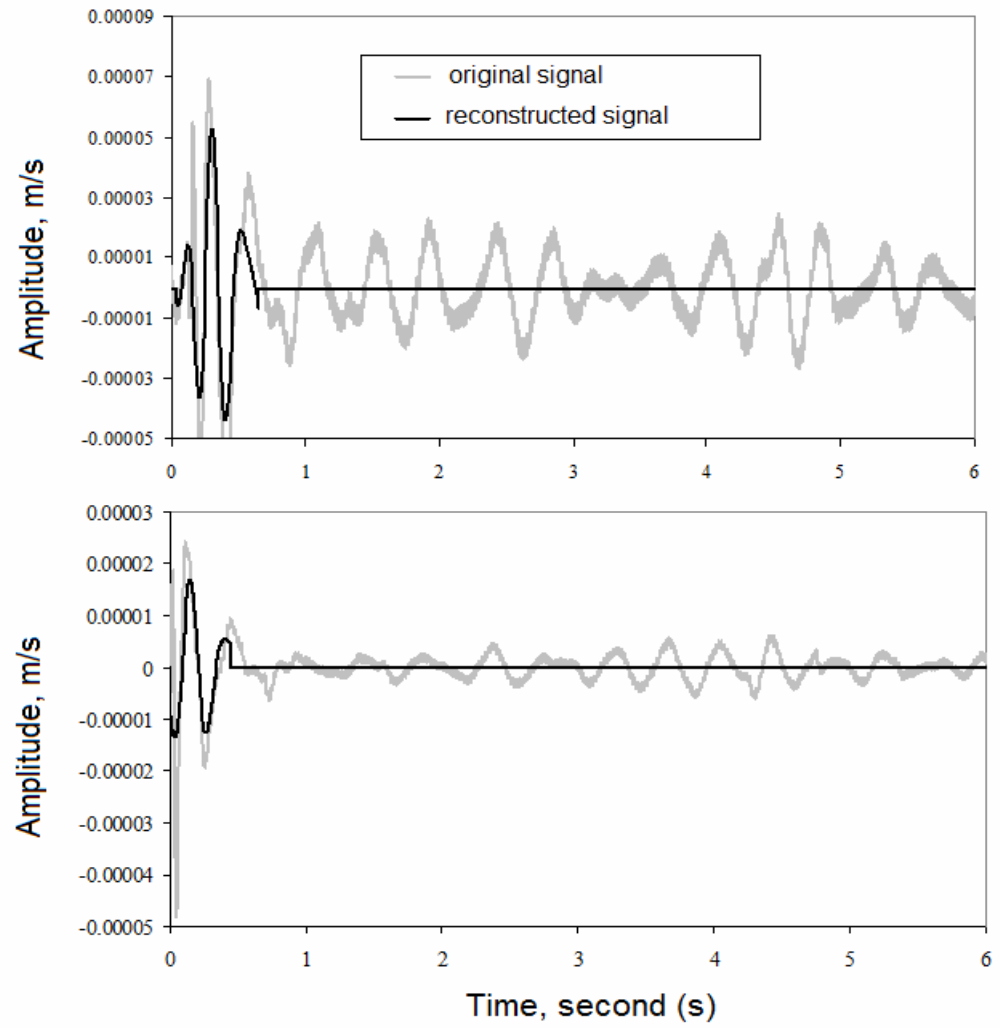

Fig. 10. Reconstructed signals from the CWTF

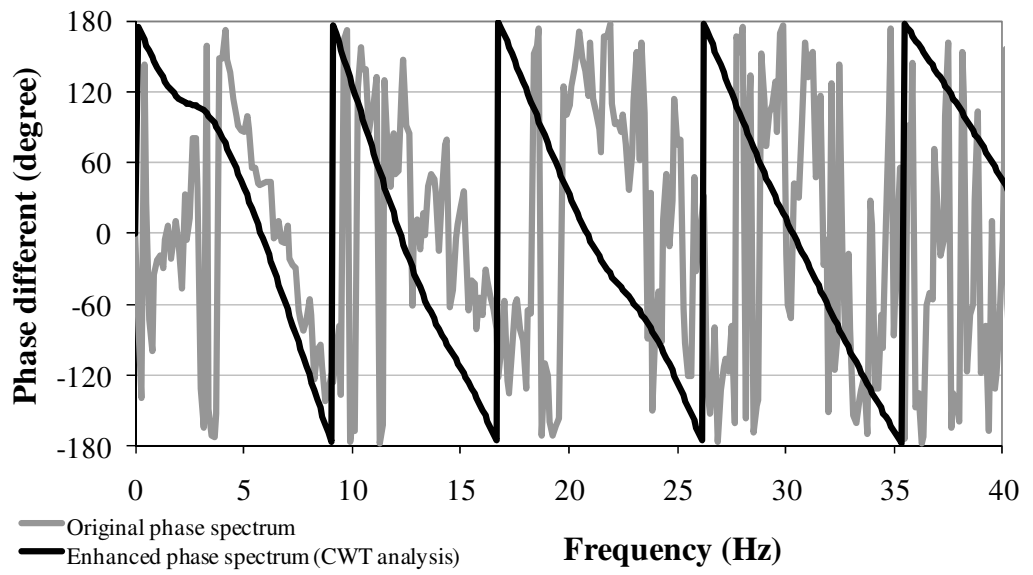

Fig. 11. Phase spectrum from two signals obtained by CWTF and spectrogram analysis compared to the original phase spectrum 


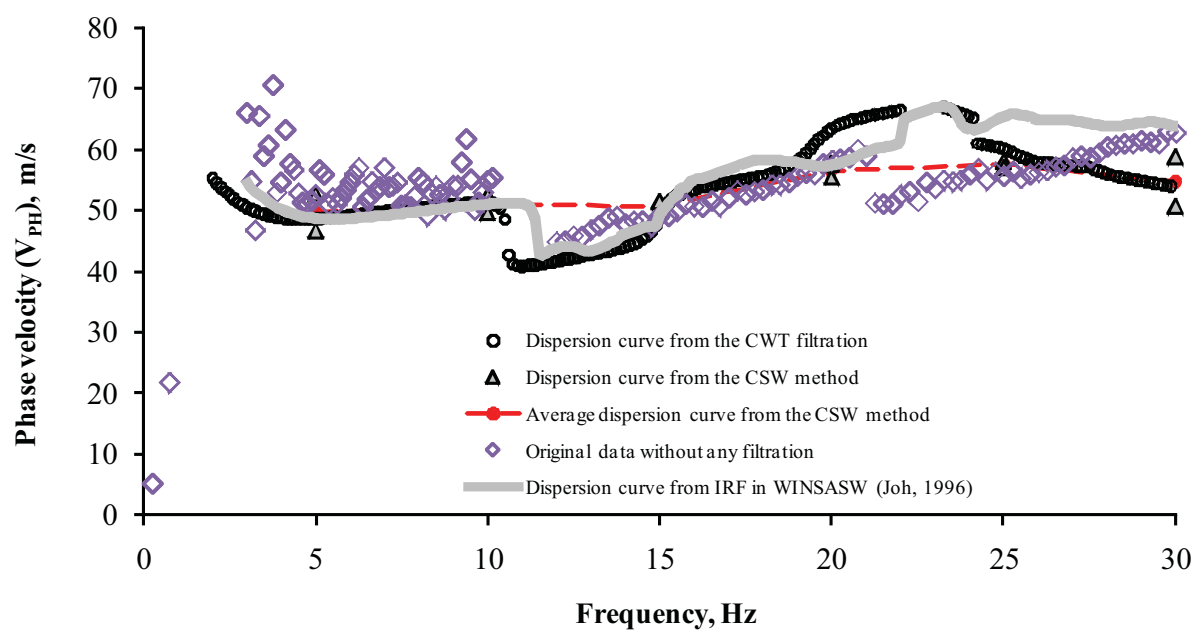

Fig. 12. Comparison between dispersion curves from the CWTF in the WSASW method and the dispersion curves from the original phase data (without any filtrations), developed by the CSW method and by impulse response filtration (IRF) built in WINSASW (Joh, 1996)

\subsection{Shear wave velocity evaluation}

The actual shear wave velocity of the soil profile is produced from the inversion of the experimental dispersion curve. In the inversion process, a profile of a homogeneous layer extending to infinity in the horizontal direction is assumed. An example shear wave velocity profile of soil site from this study is shown in Fig. 13. The average inverted shear wave velocity of soil layer for RTM Kelang test sites was found to be $54.90 \mathrm{~m} / \mathrm{s}$ with a range of 38.52 to $103.53 \mathrm{~m} / \mathrm{s}$. Using the shear wave velocity parameter, the soil material in this study could be evaluated and classified as soft clay (marine clay). The result shows that the soil classification based on the shear wave velocities is also reasonably in agreement with the laboratory tests.

As part of the validation on the results of the shear wave velocity profile obtained from this study, a steady state method or also well known as the continuous surface wave (CSW) measurement was carried out at same locations. In CSW measurement, a set of low frequency content generated from harmonic vibration source was set up in the range of 5 until $30 \mathrm{~Hz}$ with the fixed receiver spacing of $1 \mathrm{~m}$. In this frequency level, the observed soil profile can be investigated until $6 \mathrm{~m}$ of depth. The comparison between a shear wave profile determined by WSASW analysis and CSW method is also shown in Figure 13. This comparison shows that the shear wave velocity profile by a WSASW technique is in a good agreement with value of the shear wave velocity determined by CSW method.

\subsection{Shear modulus evaluation}

Based on the shear wave velocity profile, the shear modulus $(G)$ profile of RTM Kelang site can be calculated and the result is given in Fig. 14. The result of $G$ is also compared with the shear modulus calculated using Hardin \& Drnevich (1972) model and the shear modulus obtained from the CSW measurement. 


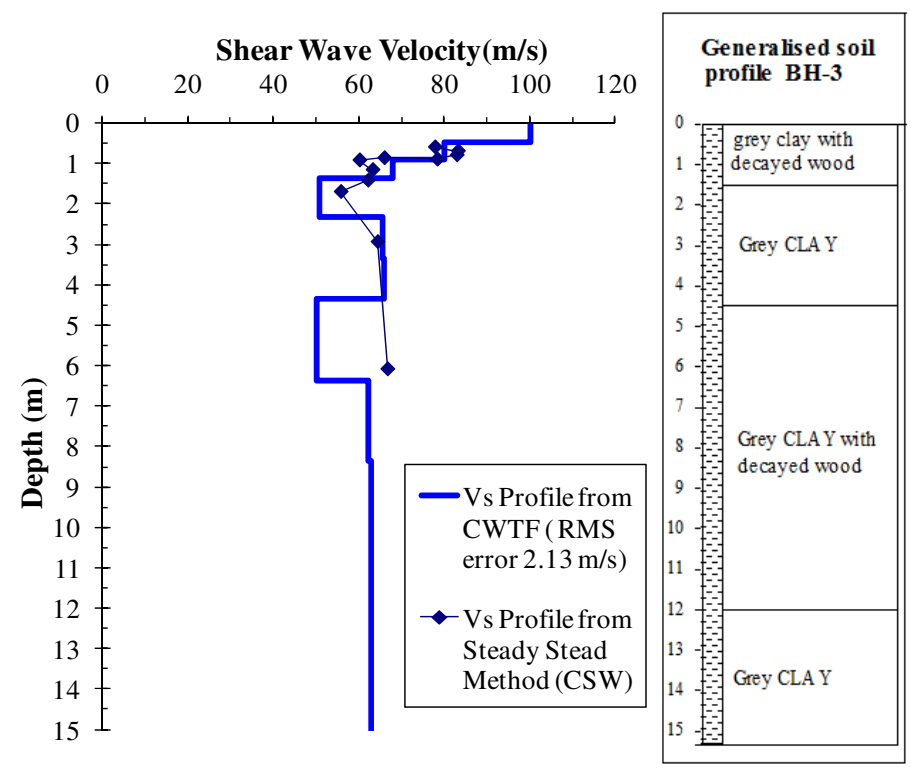

Fig. 13. A shear wave velocity profile of investigated soil at RTM Kelang site and comparison with the borehole log

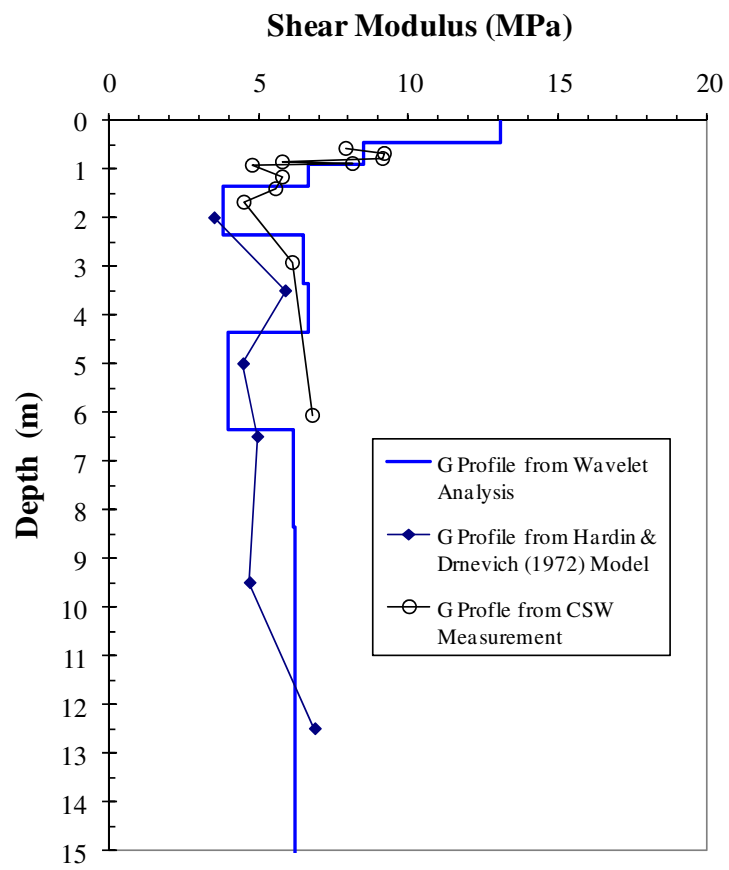

Fig. 14. A shear modulus profile of investigated soil at RTM Kelang site 
From Fig. 15 and Table 2, the soil parameters of physical properties and effective soil stresses used for the shear modulus calculation using Hardin \& Drnevich (1972) is presented. The soil parameters were obtained from the laboratory tests on soil samples collected from the drilling at the observed depth. Mathematical equation developed by Hardin \& Drnevich (1972) can be written as:

$$
G_{m a k s}=\frac{A(O C R)^{k} P_{A}^{1-n}\left(\sigma_{m}^{\prime}\right)^{n}}{F(e)}
$$

where,

A = the dimensionless elastic stiffness coeficient,

$\sigma_{m}^{\prime} \quad=$ mean effective soil stress (obtained from Fig. 15)

$P_{A} \quad=$ atmosphereic pressure,

$n \quad=$ exponent soil constant equal to 0.5 ,

$F(e) \quad=0.3+0.7 e^{2}$, and $e=$ void ratio,

$k=$ exponent soil constant depending on the plasticity index of soil,

OCR = over consolidation ratio.

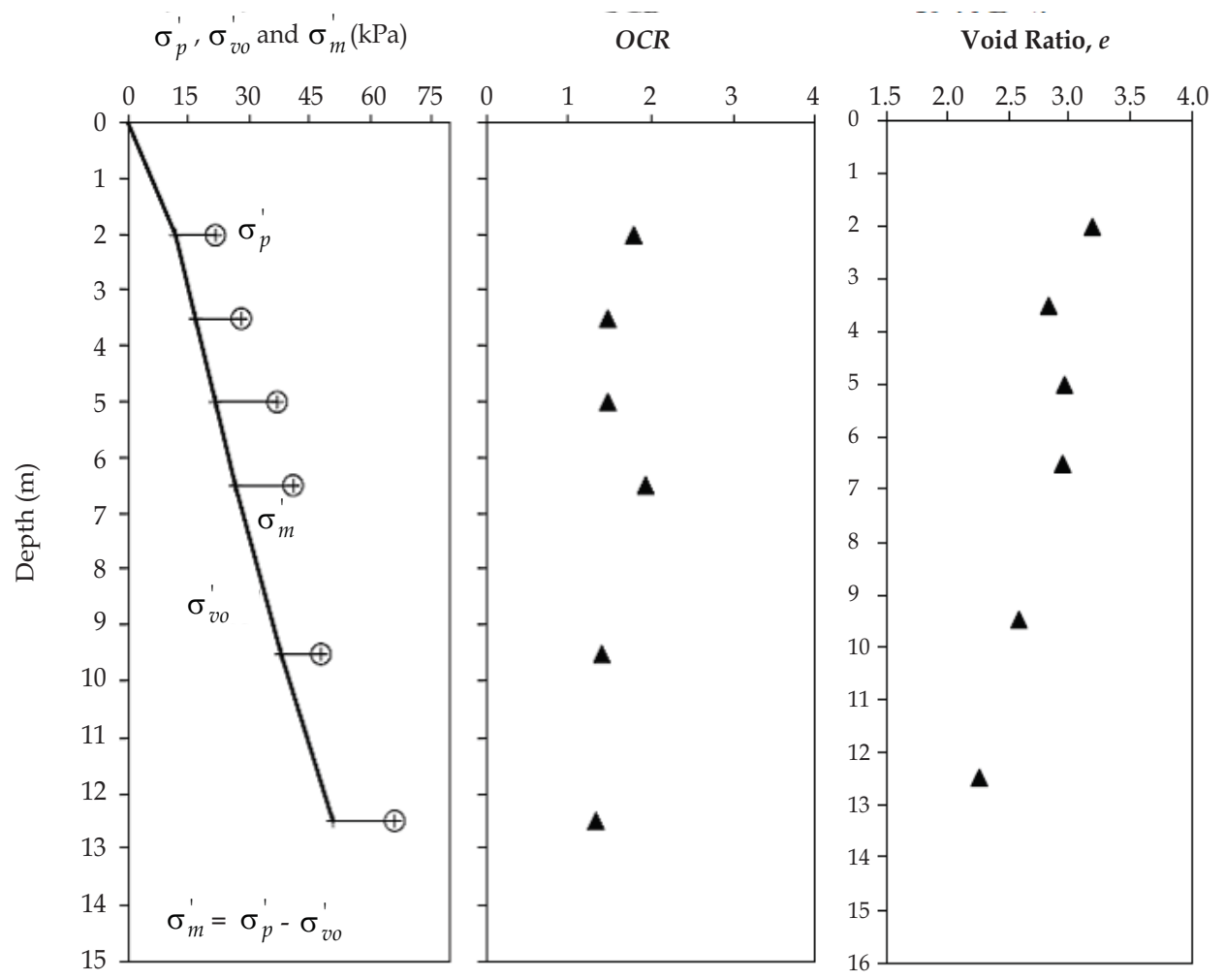

Fig. 15. Profile of soil stress, over consolidation ratio (OCR) and void ratio parameter at observed depth from the site 
Shear modulus of soil profile calculated from Hardin \& Drnevich (1972) based on laboratory soil parameter is shown in Fig. 15. From the CSW measurement, shear modulus can also be obtained based on Eq. 20. Comparing between these methods, it can be observed that a good agreement of the soil shear modulus at observed location was obtained by the wavelet spectrogram analysis of surface waves (WSASW), Hardin and Drnevich (1972) model and the continuous surface wave measurement (Fig. 14).

\begin{tabular}{|c|c|c|c|c|c|c|}
\hline Depth $(\mathrm{m})$ & $\begin{array}{c}\sigma_{m}^{\prime} \\
(\mathrm{kPa})\end{array}$ & $n$ & $k$ & $F(e)$ & OCR & $\begin{array}{c}G=G_{\text {maks }} \\
(\mathrm{MPa})\end{array}$ \\
\hline 2 & 10 & 0.5 & 0.4765 & 7.468 & 1.8 & 3.50 \\
\hline 3.5 & 20 & 0.5 & 0.3165 & 5.403 & 1.5 & 5.88 \\
\hline 5 & 12 & 0.5 & 0.4415 & 5.788 & 1.5 & 4.47 \\
\hline 6.5 & 14 & 0.5 & 0.3165 & 5.788 & 1.9 & 4.95 \\
\hline 9.5 & 10 & 0.5 & 0.311 & 4.675 & 1.4 & 4.69 \\
\hline 12.5 & 16 & 0.5 & 0.366 & 4.003 & 1.3 & 6.88 \\
\hline
\end{tabular}

Table 2. Soil parameters used for shear modulus calculation using Hardin \& Drnevich (1972) model at the site

\subsection{Shear damping ratio evaluation}

Fig. 16 shows the wavelet spectrum of $80 \mathrm{~cm}$ receiver spacing for signals received by geophone 1 and 2, respectively. The decay factor curve of the R-wave for the experimental data is then obtained from the plot of the ratio of the second signal magnitude from spectrogram $\left(w_{2}\right)$ over the first signal magnitude $\left(w_{1}\right)$ versus frequency (Fig. 17) where the curve shows a general trend of frequency dependency. A regression analysis is then performed on the experimental data to obtain the decay factor. The theoretical regression analysis of attenuation derived from equation 21 can then be written as:

$$
\ln \left[\frac{W_{f}^{R_{2}}(u, s)}{W_{f}^{R_{1}}(u, s)}\right]=-\alpha(f)(\Delta R)+k=-2 \alpha_{0}(f)+k
$$

The best-fit curve is then established between the decay factor of the experimental data and the regression analysis equation by trial and error for different values of $\alpha_{0}$ from visual bestfit evaluation of the two curves. From Fig. 17, the best-fit value of frequency-independent attenuation coefficient of the soil is calculated as $5 \times 10^{-3} \mathrm{~s} / \mathrm{m}$ at frequency of 3 to $20 \mathrm{~Hz}$. The frequency range of the attenuation coefficient of the R-waves in the soil layers was chosen using the bandwidth criteria. The root mean square error for this fitting curve is found to be 0.27 .

By repeating the procedure for attenuation analysis in each frequency value for all seismic data, the experimental attenuation curve is subsequently generated. An example of attenuation versus frequency curve at the soil site is presented in Fig. 18a. By knowing the experimental attenuation profile, the shear damping ratio can be obtained by inversion process as mentioned in Section 2.4. In the inversion analysis, the soil model is typically assumed as the homogeneous linear elastic layers over a halfspace with model parameter of shear wave velocity, shear damping ratio and thickness for each layer. In this study, due to shear damping ratio is unknown data and there is no prior information from the previous 

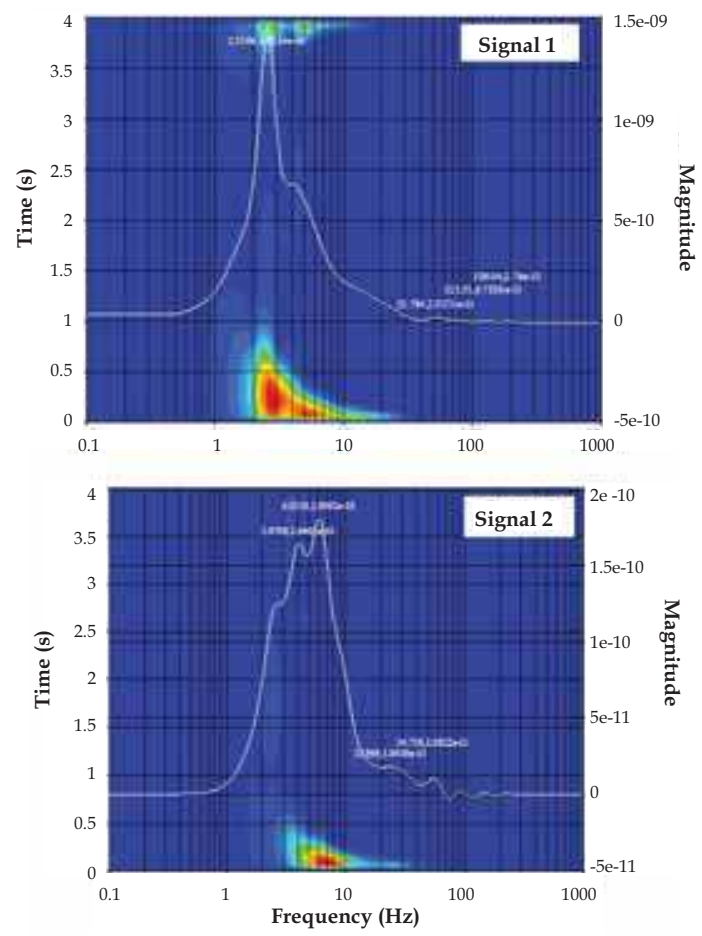

Fig. 16. The wavelet spectrum of $80 \mathrm{~cm}$ receiver spacing for signals received by geophone 1 and 2

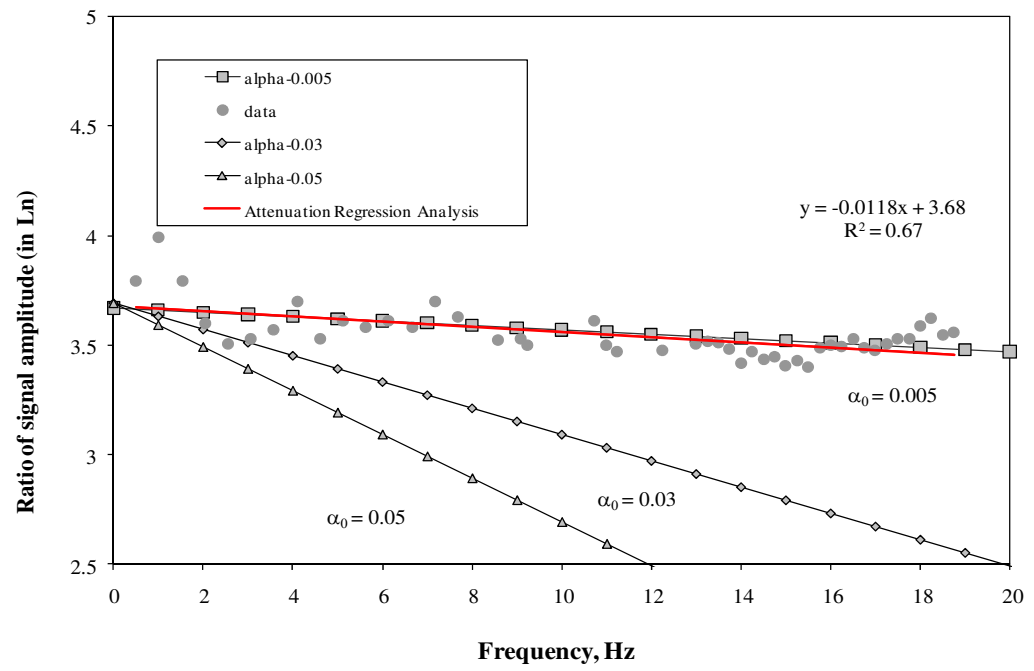

Fig. 17. The best-fit frequency-independent attenuation coefficient of the soil based on attenuation regression analysis 
Attenuation $(\alpha), 1 / \mathrm{m}$

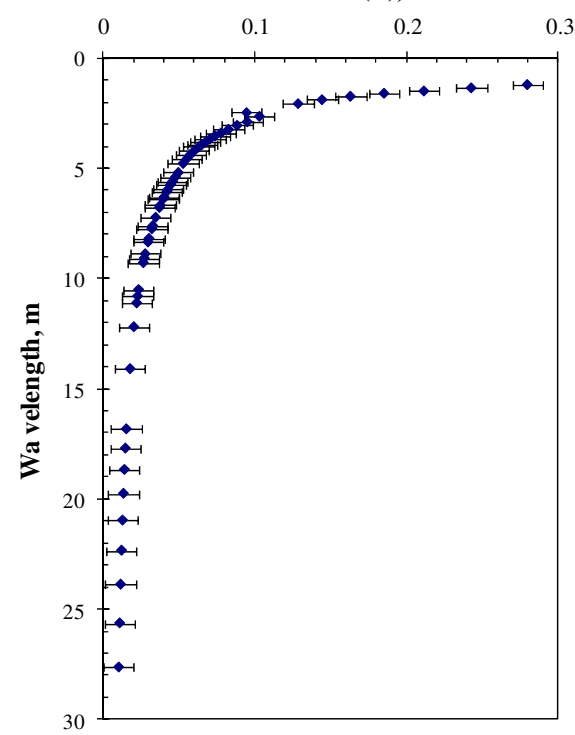

Attenuation $(\alpha), 1 / \mathrm{m}$

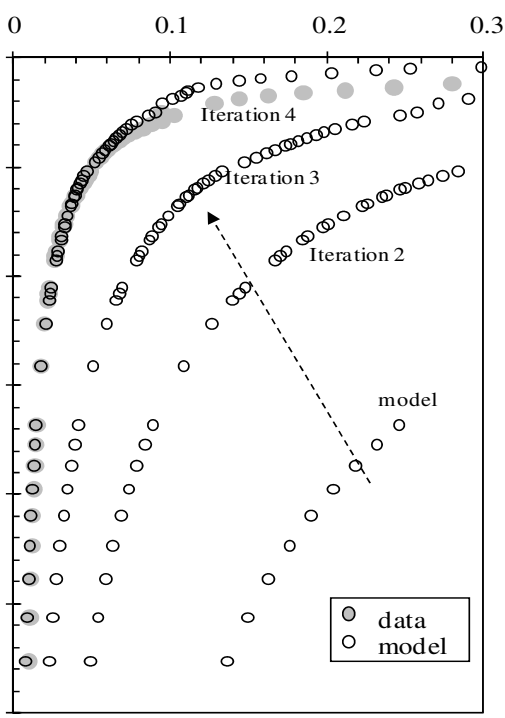

Fig. 18. (a) An example of experimental attenuation versus frequency curve at the soil site and (b) iteration process in the inversion analysis for fitting of theoretical attenuation curve to the experimental curve

\section{Shear Damping (\%)}

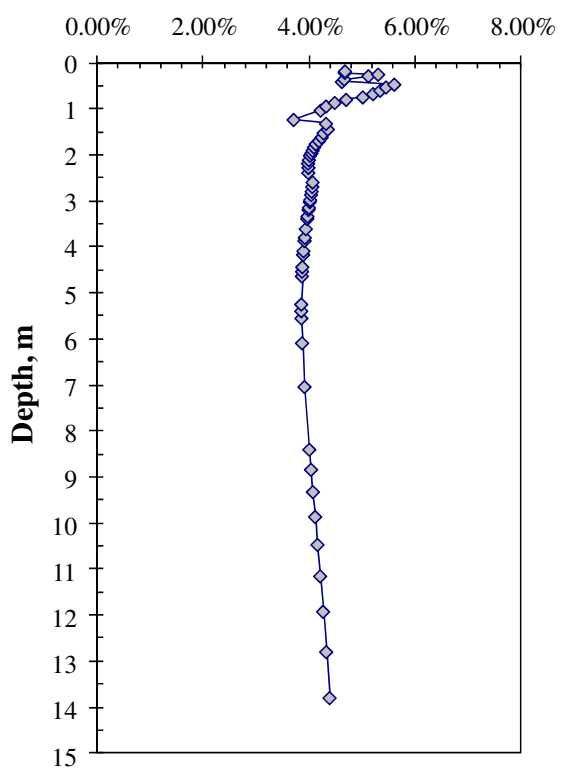

Fig. 19. Final shear damping ratio for the soil site 
field or laboratory soil data, therefore, it should be assumed with rational values for soil model parameter. The inversion analysis is procesed by using Herrmann (1994) code based on a weighted, damped, least-squares algorithm. Fig. 18b shows comparisons between the experimental attenuation curves and the theoretical attenuation data calculated from equation 22. Iteration processes were conducted to match between both experimental and theoretical curves. Fig. 19 presents the final profiles of shear damping ratio for the last iteration of the inversion process with lowest RMS error.

\section{Conclusion}

In this paper, an improved seismic method of the wavelet spectrogram analysis of surface waves (WSASW) technique for measurement of the soil dynamic property at soft soil site is presented. The identification, denoising and reconstruction technique of the wave response spectrum from seismic surface wave propagation on a residual soil using time-frequency analysis of continuous wavelet transforms is also proposed. The mother wavelet of Morlet was used for providing good resolution of spectrogram at low frequency and is also effective in the detection of low frequency noises. The spectrogram could be used to clearly identify the various events of interest of the seismic surface waves and noisy signals. Based on the generated spectrogram, the thresholds for CWT filtration could be easily obtained. Consequently, the denoised signals of the seismic surface waves were able to be reconstructed by inverse wavelet transform considering the thresholds of the interested spectrum.

A good agreement was obtained between the dispersion curve obtained from the phase spectrum based on the CWT filtration used in WSASW method compared to the dispersion curve analysed from the IRF technique and the experimental dispersion curve from the CSW measurement. The technique is also able to evaluate the soil dynamic properties, i.e., shear wave velocity, shear modulus and damping ratio properties at soft clay soil site as performed in this study. Comparison between the shear wave velocity and shear modulus obtained using WSASW method compared to that of the WSASW and Hardin \& Drnevich (1972) model were found to be good match. Finally, the WSASW technique based on wavelet analysis is a potential tool and useful for identification and evaluation of the transient events in nonstationary signals produced from the seismic measurement at the soft soil sites.

\section{Acknowledgment}

The support for this work was provided in part by Hibah Bersaing Grant 2009 SP2H No. 058/SP2H/PP/DP2M/IV/2009 from the Ministry of National Education, Indonesia and research project with Jabatan Kerja Raya (JKR) Malaysia. These supports are gratefully acknowledged. Authors would also like to grateful appreciate to Mr. Khairul Anuar Mohd. Nayan and Mr. Mecit Kurt for their assistances in the field measurement.

\section{References}

Aki, K. \& Richards, P.G. (1980). Quantitative Seismology, Vol.1, W.H. Freeman \& Co., ISBN: 978-0716710585, San Fransisco.

Capilla, C. (2006). Application of the Haar Wavelet Transform to Detect Microseismic Signal Arrivals, Journal of Applied Geophysics, Vol. 59, No.1, (May 2006), pp. 36-46, ISSN: 0926-9851. 
Chik, Z., Islam, T., Mustafa, M.M., Sanusi, H., Rosyidi, S.A. \& Taha, M.R. (2009). Surface Wave Analysis Using Morlet Wavelet in Geotechnical Investigations, Journal of Applied Sciences, Vol.9, No.19, pp. 3491-3501, ISSN: 18125654.

Daubechies, I. (1992). Ten Lecturers on Wavelets, ISBN: 978-0898712742, Society of Industrial and Applied Mathematics, Pennsylvania.

Foti, S. (2004). Using Transfer Function for Estimating Dissipative Properties of Soils from Surface-Wave Data, Near Surface Geophysics, Vol.2, (November 2004), pp.231-240, ISSN: 1569-4445.

Foufoula-Georgiou, E. \& Kumar P. (1995). Wavelets in Geophysics: An Introduction, In: Wavelet in Geophysics, E. Foufoula-Georgiou \& P. Kumar (Eds.), Academic Press, ISBN: 9780122628504, California.

Ganji, V., Gucunski, N., \& Nazarian, S. (1998). Automated Inversion Procedure for Spectral Analysis of Surface Waves, Journal of Geotechnical \& Geoenvironmental Engineering, Vol.124, No.8, (August 1998), pp. 757-770, ISSN: 1090-0241.

Hardin, B.O. \& Drnevich, V.P. (1972). Shear Modulus and Damping in Soils: Measurement and parameter effects. Journal of Soil Mechanics and Foundations Division, Vol.98, No.6, (June 1972), pp. 603-624, ISSN: 0044-7994.

Heisey, J.S., Stokoe II, K.H. \& Meyer, A.H. (1982). Moduli of Pavement System from Spectral Analysis of Surface Wave, Transportation Research Record, No.852, pp. 22-31, ISSN: 0738-6826.

Herrmann, R.B. (1994). Computer Programs in Seismology, User's Manual, St.Louis University, Missouri, USA.

Joh, S.H. (1996). Advance in Interpretation and Analysis Technique for the Spectral Analysis of Surface Wave (SASW) Measurements, Ph.D. Dissertation, the University of Texas at Austin.

Kausel, E. \& Röesset, J.M. (1981). Stiffness Matrices for Layered Soils, Bulletin of the Seismological Society of America, Vol.71, No.6, (December 1981), pp. 1743-1761, ISSN: 0037-1106.

Kim, D.-S. \& Park, H.-C. (2002). Determination of Dispersion Phase Velocities for SASW method Using Harmonic Wavelet Transform, Soil Dynamics and Earthquake Engineering, Vol.22, No.8, (September 2002), pp.675-684, ISSN: 0267-7261.

Kramer, S.L. (1996). Geotechnical Earthquake Engineering, ISBN: 978-8129701930, Prentice-Hall, New Jersey.

Kritski, A., Vincent, A. P., Yuen, D. A. \& Carlsen, T. (2007). Adaptive Wavelets for Analyzing Dispersive Seismic Waves, Geophysics, Vol.72, No.1, (February 2007), pp. V1-V11, ISSN: 0016-8033.

Lai, C.G. \& Rix, G.J. (1998). Simultaneous Inversion of Rayleigh Phase Velocity and Attenuation for Near-Surface Site Characterization, Report No.GIT-CEE/GEO-98-2, Georgia Institute of Technology.

Liu, P.C. (1994). Wavelet Spectrum Analysis and Ocean Wind Waves. In Wavelets in Geophysics, E. Foufoula-Georgiou \& P. Kumar (Eds.), 151-166, Academic Press, ISBN: 9780122628504, California.

Mallat, S. (1989). A Theory for Multiresolution Signal Decomposition: The wavelet Representation, IEEE Transactions on Pattern Analysis and Machine Intelligence, Vol.11, pp.674-693, ISSN: 0162-8828.

Meyers, S.D., Kelly, B.G. \& O'Brien, J.J. (1993). An Introduction to Wavelet Analysis in Oceanography and Meteorology: With Application to the Dispersion of Yanai Waves, Monthly Weather Review, No.121, pp.2858-2866, ISSN: 0027-0644. 
Nazarian, S. \& Stokoe II, K.H. (1986). In Situ Determination of Elastic Moduli of Pavement Systems by Spectral-Analysis-of-Surface-Wave Method (Theoretical Aspects), Research Report 437-2, Center of Transportation Research, Bureau of Engineering Research, the University of Texas at Austin.

Nazarian, S. (1984). In Situ Determination of Elastic Moduli of Soil Deposits and Pavement Systems by Spectral-Analysis-of-Surface-Wave method, Ph.D. Dissertation, the University of Texas at Austin.

Rosyidi, S.A., Taha, M.R., Ismail, A. \& Chik, Z. (2009). Enhanced Signal Reconstruction of Surface Waves on SASW Measurement Using Gaussian Derivative Wavelet Transform, Acta Geophysica, Vol.57, No.3, (September 1999), pp. 616-635, ISSN: 1895-6572.

Rosyidi, S.A.P (2009). Wavelet Analysis of Surface Wave for Evaluation of Soil Dynamic Properties, Ph.D. Thesis, the National Universiti of Malaysia, Bangi.

Rosyidi, S.A.P. (2011). Use of Wavelet Analysis and Filtration on Impulse Response for SASW Measurement In PCC Slab of Pavement Structure, Contemporary Topics on Testing, Modeling, and Case Studies of Geomaterials, Pavements, and Tunnels, Geotechnical Special Pulblication 215, American Society of Civil Engineers, pp. 74-82, ISBN: 978-0-7844-7626-0.

Shokouhi, P., Gucunski, N. \& Maher, A. (2003). Application of Waveles in Detection of Cavities under Pavements by Surface waves, Transportation Research Record No.1860, pp. 57-65, ISSN: 0738-6826.

Soman, K.P. \& K.L. Ramachandran (2005). Insight into Wavelets from Theory to Practice, Prentice-Hall of India, ISBN: 9788120340534, New Delhi.

Stokoe II, K.H., Wright, S.G., Bay, J.A. \& Röesset, J.M. (1994). Characterization of Geotechnical Sites by SASW Method. In Geophysical Characterization of Sites, R.D. Woods (Ed.), 15-25,Oxford Publishers, ISBN: 97818811570363, New Delhi.

Torrence, C. \& Compo, G.P. (1998). A Practical Guide to Wavelet Analysis, Bulletin of the American Meteorological Society, Vol.79, No.1, (January 1998), pp. 61-78, ISSN: 0003-0007.

Viktorov I.A. (1967). Rayleigh and Lamb Waves: Physical Theory and Applications, Plenum Press, ISBN: 0306302861, New York.

Wang, B. \& Wang, Y. 1996. Temporal Structure of the Southern Oscillation as Revealed by Waveform and Wavelet Analysis, Journal of Climate, No.9, No.7, (July 1996), pp. 1586-1598, ISSN: 0894-8755.

Weng, H. \& Lau, K.M. (1994). Wavelets, Period Doubling and Time-Frequency Localization With Application to Organization of Convection Over the Tropical Western Pasific, Journal of the Atmospheric Sciences, Vol.51, No.17, (Spetember 1994), pp. 2523-2541, ISSN: 0022-4928.

Xia J., Miller, R.D., Park, C.B. \& Tian, G. (2002). Determining Q of Nearsurface Materials from Rayleigh waves, Journal of Applied Geophysics, Vol.51, No.2-4, (December 2002), pp.121-129. 


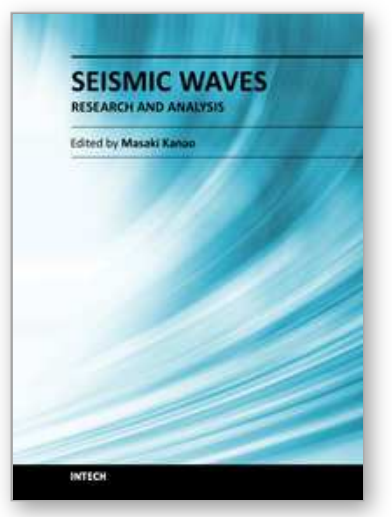

\author{
Seismic Waves - Research and Analysis \\ Edited by Dr. Masaki Kanao
}

ISBN 978-953-307-944-8

Hard cover, 326 pages

Publisher InTech

Published online 25, January, 2012

Published in print edition January, 2012

The importance of seismic wave research lies not only in our ability to understand and predict earthquakes and tsunamis, it also reveals information on the Earth's composition and features in much the same way as it led to the discovery of Mohorovicic's discontinuity. As our theoretical understanding of the physics behind seismic waves has grown, physical and numerical modeling have greatly advanced and now augment applied seismology for better prediction and engineering practices. This has led to some novel applications such as using artificially-induced shocks for exploration of the Earth's subsurface and seismic stimulation for increasing the productivity of oil wells. This book demonstrates the latest techniques and advances in seismic wave analysis from theoretical approach, data acquisition and interpretation, to analyses and numerical simulations, as well as research applications. A review process was conducted in cooperation with sincere support by Drs. Hiroshi Takenaka, Yoshio Murai, Jun Matsushima, and Genti Toyokuni.

\title{
How to reference
}

In order to correctly reference this scholarly work, feel free to copy and paste the following:

Sri Atmaja P. Rosyidi and Mohd. Raihan Taha (2012). Wavelet Spectrogram Analysis of Surface Wave Technique for Dynamic Soil Properties Measurement on Soft Marine Clay Site, Seismic Waves - Research and Analysis, Dr. Masaki Kanao (Ed.), ISBN: 978-953-307-944-8, InTech, Available from:

http://www.intechopen.com/books/seismic-waves-research-and-analysis/wavelet-spectrogram-analysis-ofsurface-wave-technique-for-dynamic-soil-properties-measurement-on-so

\section{INTECH}

open science | open minds

\section{InTech Europe}

University Campus STeP Ri

Slavka Krautzeka 83/A

51000 Rijeka, Croatia

Phone: +385 (51) 770447

Fax: +385 (51) 686166

www.intechopen.com

\section{InTech China}

Unit 405, Office Block, Hotel Equatorial Shanghai

No.65, Yan An Road (West), Shanghai, 200040, China

中国上海市延安西路65号上海国际贵都大饭店办公楼405单元

Phone: +86-21-62489820

Fax: $+86-21-62489821$ 
(C) 2012 The Author(s). Licensee IntechOpen. This is an open access article distributed under the terms of the Creative Commons Attribution 3.0 License, which permits unrestricted use, distribution, and reproduction in any medium, provided the original work is properly cited. 